\title{
COMENTARIOS EXEGÉTICO-DOCTRINARIOS SOBRE LAS LEYES NACIONALES DE ARBITRAJE COMERCIAL INTERNACIONAL DE URUGUAY Y ARGENTINA ${ }^{1}$
}

\author{
EXEGETICAL-DOCTRINAL COMMENTS ON THE \\ NATIONAL LAWS OF INTERNATIONAL COMMERCIAL \\ ARBITRATION OF URUGUAY AND ARGENTINA
}

\section{COMENTÁRIOS EXEGÉTICO DOUTRINÁRIOS SOBRE AS LEIS NACIONAIS DE ARBITRAGEM COMERCIAL INTERNACIONAL DE URUGUAI E ARGENTINA}

\author{
ALEJANDRO FERREIRA*
}

RESUMEN: El Arbitraje Comercial Internacional es un área que cobra cada vez más importancia en las Relaciones Internacionales al convertirse en la piedra angular para solucionar las controversias entre los distintos operadores del comercio internacional debido a su practicidad, especialidad, celeridad e informalidad. Por esta razón, resulta imperante un análisis exhaustivo de los principales aspectos de las leyes nacionales sobre ACI aprobadas por la República Oriental del Uruguay y la República Federativa de Argentina. En estas páginas el lector encontrará un análisis detallado de los principales aspectos consagrado por las Leyes Nacionales de Arbitraje Comercial Internacional inspiradas en el proyecto de Ley Modelo de la UNCITRAL.

PALABRAS CLAVE: UNCITRAL, Arbitraje Comercial Internacional, Argentina, Uruguay, Armonización, Derecho Internacional Privado.

ABSTRACT: International Commercial Arbitration is an area that is becoming increasingly important in International Relations, constituting the cornerstone to solve controversies between different operators of International Trade due to its practicality, specialty, speed, as well as informality. For this reason, a comprehensive emphasis on the main aspects of the national laws on commercial arbitration approved by Uruguay and

\footnotetext{
Licenciado en Relaciones Internacionales en la Universidad de la República. Maestrando en Ciencia Política. Aspirante a Docente en Derecho Internacional Público e Historia de las Relaciones Internacionales. Fundador y responsable del primer blog sobre Relaciones Internacionales en Uruguay. Miembro del Centro de estudios de la propiedad intelectual (CEPI) y de la Escuela Latinoamericana de la Propiedad Intelectual (ELAPI). ORCID 0000-0001-5318-5334. alerourrii2017@gmail.com

1 Trabajo basado en la Monografía final de grado para la obtención del Título Licenciado en Relaciones Internacionales defendida el 26 de febrero del 2020 aprobada con nota SSS (12) por el tribunal compuesto por la Dra. Beatriz Bugallo Montaño, la Dra. Laura Capalvo y el Dr. Lic. Marcos Dotta Salgueiro y bajo la tutoría de la Dra. Ana de Llano Ramírez.
} 
Argentina is imperative. Through these pages, the reader will access a detailed analysis of the main aspects enshrined in the National Commercial Arbitration laws inspired by the Model Bill of UNCITRAL

KEY WORDS: UNCITRAL, International Commercial Arbitration, Argentina, Uruguay, Armonization, Private International Law

RESUMO: A Arbitragem Comercial Internacional é uma área que adquire cada vez mais importância nas Relações Internacionais ao tornar-se a pedra angular para solucionar as controvérsias entre os diferentes operadores do comércio internacional devido à sua praticidade, especialidade, rapidez e informalidade. Por esta razão, é imperante uma análise exaustiva dos principais aspectos das leis nacionais sobre ACI aprovadas pela República Oriental do Uruguai e a República Federativa da Argentina. Nestas páginas, o leitor encontrará uma análise detalhada dos principais aspectos consagrados pelas Leis Nacionais de Arbitragem Comercial Internacional inspiradas no projeto de Lei Modelo da UNCITRAL.

PALAVRAS-CHAVE: UNCITRAL, Arbitragem Comercial Internacional, Argentina, Uruguai, Harmonização, Direito Internacional Privado.

\section{INTRODUCCIÓN}

El Arbitraje Comercial Internacional ${ }^{2}$ (en adelante ACI) es un área que cobra cada vez más importancia en las Relaciones Internacionales (en adelante RRII) al convertirse en la piedra angular para solucionar las controversias entre los distintos operadores del comercio internacional debido a su practicidad, especialidad, celeridad e informalidad.

En este artículo estaremos realizando un análisis sobre la reciente aprobación de las Leyes Nacionales sobre ACI uruguaya y argentina (en adelante LNA y LNAU respectivamente). A través de estas, se procuró "la armonización de los regímenes nacionales en materia de arbitraje internacional" (Talice, 2019, p.25) con el fin de dar seguridad y confianza a los distintos agentes intervinientes en los negocios internacionales. Antes de esto, apreciábamos que ambos países eran uno de los pocos en el mundo que todavía presentaban como solución etática las disposiciones de sus códigos procedimentales civiles (sumado al debate doctrinario en el caso uruguayo) en la regulación jurídica del ACI, aspecto negativo para su inserción internacional y criticados por la doctrina de diversas latitudes. ${ }^{3}$

Como señalan Carboneau, Gary Born y Paul Arreghi, los distintos operadores del comercio internacional buscan países para la concreción de arbitrajes en base a prin-

2 En este trabajo consideraremos que el ACI es Es "un proceso por el cual las partes presentar de manera consensuada una controversia a un responsable de la toma de decisiones no gubernamental, seleccionado por o para las partes, para dictar una decisión vinculante que resuelva una controversia de conformidad con la neutral" (Gary Born, 2011 p.33). O tambien "un método contractual para resolver controversias. Por su contrato, las partes acuerdan confiar las diferencias entre ellos a la decisión de un árbitro o panel árbitros, con exclusión de los tribunales, y se obligan a aceptar esa decisión, una vez tomada, si lo piensan bien o no. (Methanex Motunui Ltd v Spellman, 2004 op cit. Gary Born p. 33).

3 Y como señala Paul Arreghi "Ese fenómeno era por demás extraño ya que Argentina y Uruguay son naciones de una innegable valiosa tradición jurídica y especialmente porque eran parte, desde hacía mucho tiempo, de las más importantes convenciones sobre $A C I^{\prime \prime}(2019$, p.1). 
cipios estructurales (neutralidad, buena ubicación geográfica, estabilidad, etc.) y jurídicas (haber ratificado la Convención de Nueva York, las convenciones interamericanas y tener una doctrina y jurisprudencia, favorable a la continuidad jurídica de los laudos arbitrales.

El interés por indagar sobre el ACI tiene su génesis en un hecho fáctico central. Los Estados no son los únicos creadores de normas jurídicas vinculantes ni tienen el monopolio para impartir justicia. En diversas ramas de la actividad humana (el deporte, relaciones de consumo, compraventa de mercaderías, temas de propiedad intelectual, seguros, obras de arte y patrimonio cultural, entre otros), tenemos la posibilidad de elegir un derecho extra-etatico y conjuntamente denegar la jurisdicción internacional competente, establecida por las normas de Derecho Internacional Privado (en adelante DIPR) en pos de institutos de carácter extraestatal. De esta manera los laudos emitidos por los diferentes tribunales estatales serán reconocidos por los demás y asimilados en su tratamiento a las sentencias dictadas por dichas autoridades estaduales y la normativa para-estatal elegida por las partes será considerada ley aplicable.

En las siguientes páginas, estaré presentando los aspectos medulares de las leyes objeto de esta investigación. Para ello me basare en la noción de la lex arbitrii en torno a dos conceptos aportados por la escuela alemana de derecho: Anwendungsbereich (ámbito de aplicación) y Geltungsbereich (ámbito de validez). Estos determinan primeramente las condiciones que se deben cumplir para subsumir la relación jurídica privada e internacional en ambas leyes (condiciones de calificación). Una vez que se configuran, debemos proceder al cumplimiento de las condiciones de validez (la cláusula arbitral, la correcta composición del tribunal arbitral entre otros).

\section{INTERNACIONALIZACIÓN Y EXCLUSIVISMO DEL ARBITRA- JE COMERCIAL INTERNACIONAL}

El primer eslabón del Anwendungsbereich tiene asidero en que una determinada controversia sea pasible de ser subsumible en el ámbito de aplicación del DIPR. La teoría general del mismo nos explica que deberán existir elementos de extranjería relevantes, ya sea reales, personales o conductuales. En este caso, nos encontramos en el universo de la conexión conductual, a través de la cual las partes pueden determinar (con mayor o menor nivel de flexibilidad) el derecho aplicable ${ }^{4}$, o como es este caso, el juez competente. En materia específica, la internacionalización del ACI vendrá dada por elementos históricos, doctrinarios y positivos. En el primero de los casos, como señala Talice, las primeras consideraciones en torno dicha cuestión vinieron dadas por la escuela francosuiza (la cual va por la segunda reforma de su legislación arbitral) y los mismos lo vincularon a una condición estrictamente económica $(1974, \text { p.32) })^{5}$. En cuanto a los criterios

4 En el DIPR primero debemos determinar si el caso posee algún elemento de extranjería relevante, para posteriormente realizar una "operación metodológica" (Idiarte, 2016, p.71) para subsumirlo (calificar) en una determinada categoría del cuadro ofrecido por el DIPR. Esto se lleva a cabo determinando la fuente correspondiente de conformidad con los criterios positivos vigentes (en este caso, art. 27 de la Convención de Viena sobre Derecho de los Tratados, art. 1 de la Convención de Normas generales sobre DIPR, art. 525 del CGP).

5 La jurisprudencia uruguaya consideró este mismo criterio para la internacionalización de los contratos en las sentencias. 
teóricos para determinar la internacionalidad, observamos las posturas de Rubén Santos y Paul Arreghi. El primero de ellos menciona aspectos de procedimiento y objeto y el segundo un método jurídico, económico o "ecléctico". Ambos autores nos ayudan a tener elementos distintos a los establecidos por las normas del sistema de DIPR, debido a que si consideramos sólo el derecho positivo estaríamos subsumiendo un caso en las normas de DIPR sin saber de antemano si posee algún elemento de extranjería relevante.

En la presentación de las soluciones jurídicas debe partirse por el ámbito supranacional institucional en el cual tenemos el DIPR dado por los países miembros del MERCOSUR, materializado en dos protocolos sobre $\mathrm{ACI}^{6}$.Estos establecieron en su ámbito de aplicación que podrán aplicarse a personas físicas o jurídicas ${ }^{7}$ surgidas de contratos comerciales internacionales (art.1) "que al momento de su celebración, tengan ya sea su residencia habitual, centro principal de sus negocios, la sede, sucursales, establecimientos o agencias en más de un Estado Parte (Art $\left.3^{9}\right)^{\prime \prime}$.

En el mencionado artículo prima el ámbito de aplicación sobre el concepto de internacionalización, puesto que, si bien existe el mismo, enmarca dentro de los límites jurídico-geográficos de los estados parte del Tratado de Asunción. Los literales b), c) y d) del mismo incorporan algunos elementos propios del desarrollo progresivo del DIPR al considerar los "contactos objetivos" económicos y jurídicos como elementos de internacionalización o para la subsunción en el ámbito de aplicación ${ }^{10}$. El último criterio es importante debido a que establece que las partes, aún sin contactos con un Estado Parte, elijan someter el diferendo en un Estado del MERCOSUR, consagrando la sumisión voluntaria a un determinado ordenamiento jurídico (similar a la disposición de la Ley Nacional de Arbitraje de Argentina art. 3 b I). En las restantes fuentes supranacionales de DIPR no se encuentran otros criterios de internacionalización (la CIDIP-I sobre ACI no lo regula). Por su parte, la convención de Nueva York sólo establece un criterio que podría considerarse "geográfico", al expresar en su artículo I.1 que "se aplicará al reconocimiento y la ejecución de las sentencias arbitrales dictadas en el territorio de un Estado distinto de aquel en el que se pide el reconocimiento y la ejecución de dichas sentencias".

6 Estos protocolos nacieron para proporcionar al sector privado de los Estados Parte del MERCOSUR métodos alternativos para la resolución de controversias surgidas de los contratos comerciales internacionales concluidos ientre personas físicas o jurídicas de derecho privado (CMC/DEC N 3/98), dada la inexistencia de leyes nacionales y recordando conjuntamente que la armonización de soluciones en el MERCOSUR es un mandato establecido por el Tratado de Asunción (art 1).

7 Debemos considerar la cuestión desde la perspectiva de Luis Osbaldo Batpista, quien plantea que la concepción, determinación y alcance de las personas jurídicas se encuentra determinada por el orden jurídico de la cual provienen (derecho sustantivo aplicable). El mismo se encuentra determinado de conformidad con los elementos de extranjería relevantes para el ordenamiento jurídico en el cual las mismas se encuentren de forma fáctica (es decir, que tendremos elementos de extranjería relevantes personas y reales actuando en conjunto). Y en este sentido, la sumisión voluntaria de una determinada empresa vendrá dada por la seguridad jurídica y las condiciones de ley aplicable y juez competente que establezca el ordenamiento jurídico donde se asienten (en los casos en que hablamos de arbitraje entre empresas). (p. 65 a $67)$.

8 Surge la cuestión de resolver cuando un contrato es internacional, para lo cual se podrían tener en cuenta las disposiciones de la Convención de Viena de 1980 (en el caso de ser compraventa internacional de mercaderías) o por doctrina mayor recibida a las disposiciones materiales de la convención interamericana sobre derecho aplicable a los contratos internacionales.

9 Como también lo prevé el artículo primero del Protocolo de Buenos Aires sobre Jurisdicción Internacional.

10 Este tema es ampliamente desarrollado en "¿Cuándo un contrato es Internacional? Análisis desde una perspectiva regional" De Gonzalo Lorenzo Idiarte, disponible en "Avances del Derecho Internacional Privado en América Latina", p. 105-132. 
A nivel de normativa de DIPR Etático, tanto en Argentina como en Uruguay tenemos que la internacionalidad del ACI no había sido considerada por la política legislativa. La aprobación de las leyes objeto de este trabajo trajo consigo un criterio uniforme para ambos países. Estos instrumentos disponen como primer criterio el tener establecimientos en Estados diferentes, solución que no es foránea para los ordenamientos jurídicos analizados porque ya se establece con la Convención de Viena sobre Compraventa Internacional de Mercaderías de 1980. La segunda causal será teniendo en cuenta el lugar del cumplimiento de una parte sustancial de las obligaciones de la relación comercial o el lugar con el cual el objeto del litigio tenga una relación más estrecha, esté situado fuera del Estado en el que las partes tienen su establecimiento. La Ley Modelo UNCITRAL (en adelante LMU) prevé, a diferencia de $\mathrm{LNAU}^{11}$ que la internacionalización podrá estar dada por el hecho de que el arbitraje se realice en un país distinto al del Establecimiento. Cómo señalan Mateo Verdias Mezzera y Joaquín Garino Podestá en Uruguay, "es evidente que se buscó específicamente evitar que las partes evadieron las disposiciones del Código General del Proceso (en adelante CGP) en cuanto al arbitraje doméstico, cuando resultaren aplicables." (2018, p.71). A su vez, la LNAU reafirma esta condición estableciendo expresamente que la sola voluntad de las partes no podrá determinar la internacionalidad del arbitraje, desconociendo además la disposición " $c$ " de la LMU (igual que la LNA).

Esta posición puede reflejarse en la jurisprudencia uruguaya (anterior a la aprobación de la ley), con la sentencia del Tribunal de Apelaciones en lo Civil de 1er Turno N. ii74/2011, del 23 de febrero de 2011 en la cual se establece que la internacionalidad del arbitraje no está dada por la sede del tribunal estatal ya que el mismo "resuelve un conflicto internacional... constituido por una institución extranjera, con sujeción a reglas procesales establecidas por esa misma institución y aplicando derecho extranjero" y por consiguiente se aplicarían las normas del CGP ${ }^{12}$.

En el caso argentino no sucedió lo contrario, sino que la internacionalidad dada por la sede arbitral se permitió a los efectos de que personas físicas o jurídicas con sede o establecimientos comunes en otros países (de conformidad con su normativa) pudieran elegir como sede arbitral a la Nación Argentina. En el caso inverso, operaría el art. 106 de la ley que remite al 2605 del Código Civil y Comercial de la Nación Argentina (en adelante CCCN) y el art. 107 de la ley que remite al art V de la Convención de Nueva York sobre Reconocimiento y Ejecución de Sentencias y Laudos Arbitrales (en adelante CNY) y el art. 5 de la LNA ${ }^{13}$ descartándose dicha posibilidad.

\footnotetext{
11 Puede decirse que nuestro país se adhirió a las consideraciones que se establecieron en el Report of the United Nations Commission on International Trade Law on the work of its eighteenth session (A/40/17) en el cual "se expresaron opiniones divergentes en cuanto a la conveniencia de mantener el apartado i del inciso b" el cual "debía suprimirse fundamentándose por dos razones. Una de ellas consistía en que no estaba justificado calificar como internacional a una relación meramente interna solo porque se había escogido un lugar de arbitraje situado en el extranjero. La autonomía de las partes era inaceptable en esta materia, porque permitía a las partes eludir disposiciones jurídicas obligatorias (...) La otra razón era que la disposición abarcaba no solo el caso en que el lugar del arbitraje estaba determinado en el acuerdo de arbitraje, sino también en el caso en que se había determinado posteriormente en virtud del acuerdo por ejemplo por una institución arbitral o por el tribunal arbitral. Aunque predominó la posición de mantener el inciso, Uruguay no lo consagró en su derecho positivo.

12 La sentencia se refería a un ejemplo a la inversa, al justificar que si el ACI es internacional no aplican las normas del CGP. En este caso invertí el razonamiento lógico realizado por la magistrada

13 Art. $1^{\circ}$ del CPCCN dispone que la competencia atribuida a los tribunales nacionales es improrrogable.
} 
Esta ley es aplicable únicamente a los arbitrajes comerciales, quedando excluidos los de ámbito civil y de DIP. En el caso argentino existe una particularidad jurídica y es que nos encontramos, a diferencia del Uruguay, con un país Federal que ha distribuido competencias legislativas a las provincias, sin perjuicio de haber reservado algunas al gobierno federal. Una de las competencias delegadas a las provincias es la de elaborar su propia normativa procesal. Por consiguiente, esta ley federal sobre ACI podría haber nacido en el seno de cada poder legislativo provincial (a raíz de que los temas procesales son competencias de las distintas provincias). La doctrina argentina señaló que esta ley, si bien tiene disposiciones procesales, en su esencia establece una prórroga de jurisdicción, y la regulación de los límites jurisdiccionales de los tribunales frente a los tribunales extranjeros es una competencia que las provincias le otorgaron al Gobierno Federal de la Nación. Otro diferencial con la LNAU fue la regulación, a texto expreso, de su carácter exclusivo. Por esta razón, el ACI no se regirá por el CPCCN y los demás códigos procedimentales (uno por cada provincia) ${ }^{14}$, y, en consecuencia, estos pasarán a regular (por el carácter exclusivo de la ley) sólo el ACD. Como veremos en el siguiente apartado, se establecerán formas específicas para realizar las tareas de interpretación e integración.

Es de recibo mencionar un aspecto que es netamente semántico y sustantivo. En vista de que los textos jurídicos expresan que se aplicarán a los ACI cuyo origen corresponda a relaciones comerciales ${ }^{15}$, necesitaremos abordar una definición. En su segunda nota al pie, la LMU establece que "Debe darse una interpretación amplia a la expresión "comercial" para que abarque las cuestiones que se plantean en todas las relaciones de indole comercial, contractuales o no". Acto seguido, se presenta una lista no taxativa de operaciones consideradas comerciales.

Un último elemento para destacar es la construcción, por la vía jurídica, de un sistema de regulación dualista. Esto significa que se regulará el arbitraje interno por los códigos de procedimiento civil y el ACI por la moderna normativa recientemente aprobada. Como afirma Talice, esta separación jurídica no obedece a cuestiones de naturaleza del arbitraje, sino a una cuestión que atiende a los sujetos intervinientes. En virtud de esto, el autor sostiene que para salvaguardar dicha distinción "la calificación de un arbitraje como nacional o internacional es de orden público y no puede ser alterada por la voluntad de las partes" (2019, p.50). La LMU se expresó en sentido contrario en su art. 1.c (y como vimos supra, esta disposición no fue recogida en la ley nacional de arbitraje argentina ni uruguaya).

14 Se excluyen las disposiciones contenidas en su CCCN (arts. 1649 y ss.).

15 En el 1 Report of the United Nations Commission on International trade law on the work of its eighteenth session (A/40/17) de 1985. "Se expresaron opiniones divergentes [Primero] sobre la idoneidad de la nota al pie de página en cuanto a su forma y contenido "Incluso se propuso su eliminación por entender que no tendría efecto legal (aunque todos concordaron la importancia de realizar una interpretación amplia del concepto comercial). Las dificultades presentadas estaban en torno a los sujetos, por las inmunidades que tienen los Estados; las temáticas porque podían dar a entender que si o si se debía someter a un arbitraje esos temas (recordando que existen cuestiones no arbitrables propias de cada entidad soberana). En esta comisión se destacó la participación de Hungría, aunque también asistieron miembros de China y los Estados Unidos 


\section{EL CONCEPTO DE ARBITRABILIDAD ${ }^{16}$ A PARTIR DE LA LEY MODELO UNCITRAL}

Es posible distinguir dos tipos de Arbitrabilidad; la objetiva y subjetiva. Según Rubén Santos (2002, p.72), "la primera de ellas supondría que tipos de personas, por su propia naturaleza pueden llegar a concertar un arbitraje (comercial) válido". La segunda refiere a "cuando es la materia litigiosa la que se encuentra excluida de la posibilidad de acceder a una solución arbitral" (id., p. 83).

En torno a la primera, podemos realizar los siguientes comentarios: el Estado no es sujeto de análisis cuando actúa como persona de derecho público en un ACI. Sin embargo, es discutible su participación cuando actúa como sujeto de derecho privado en una relación comercial., pudiendo someterse a un ACI con personas físicas o jurídicas (si han celebrado un acuerdo arbitral). A este respecto, la jurisprudencia uruguaya determinó en varias oportunidades la Arbitrabilidad de los conflictos en los cuales intervienen distintas entidades gubernamentales ${ }^{17}$. En el caso argentino, existen normas constitucionales (arts. 116 y 117) que establecen expresamente la imposibilidad al arbitraje por parte de organismos estatales. La Dra. Noodt Taquela entiende que, en materia de contratos administrativos, podrían ser sometidos al mismo los aspectos técnicos o relativos a la indemnización. Como señala Guillermo Andrez Muñoz, esta disposición ha ido socavándose puesto que dicho país ha celebrado diversos tratados en materia de arbitraje de inversiones los cuales tienen rango constitucional por el art. 72 inc. 2 de su Constitución.

En cuanto al examen de la segunda condición planteada por Rubén Santos, el eje vendrá dado en torno a cuáles son las normas que determinan dicha condición (Noodt Taquela, 2000, p.3). En los ordenamientos jurídicos estudiados son las normas de derecho interno contenidas en el CGP y el CPCCN las que establecen (arts. 476 y 737 respectivamente) que "No podrán someterse al proceso arbitral las cuestiones respecto a las cuales esta "prohibida la transacción"18. A nivel general se entiende que quedan excluidas todas las relaciones no patrimoniales tales como: "matrimonio, filiación, tutela, curatela y otras cuestiones de derecho de familia"19 (Noodt Taquela, 2000 p.21). Además, si observamos las disposiciones contenidas en los Códigos de Proceso penal (arts. 2 y 6 uruguayo y arts. 1 y 5 argentino) dicha materia no será pasible de ser sometida al arbitraje. Las nuevas leyes sobre ACI que incorporaron ambos países, no tratan directamente este tema, debiendo considerarlo subsumido en el ámbito del derecho interno (imperando todavía una especie de neo-territorialismo). En este sentido, dividiremos las aguas en tres aspec-

16 Esta supone "una condición específica relacionada con el aspecto jurisdiccional de los acuerdos de arbitraje y una condición precedente para que el tribunal asuma jurisdicción sobre una disputa en particular" (Breakoulakis, 2009, p.21). Del mismo modo podemos afirmar que esta plasma la determinación de la frontera jurídica entre la autonomía de la voluntad (para someterse a un TA) y los limites objetivos establecidos por las autoridades estaduales (Lukas A Mistelis, 2008, p.4).

17 Caso 113, 1594, 1667, 5339 y 13.288 de la justicia uruguaya.

18 En cuanto a la definición de transacción debemos recurrir a los artículos 2153 a 2155 del CC y a los 832 a 861 del CCCN. A su vez el art 472 del CGP uruguayo establece que en principio se podrán someter todas las contiendas ante un tribunal arbitral, "salvo expresa disposición legal en contrario".

19 Debemos destacar ciertamente que el anterior proyecto de ley sobre Arbitraje Comercial internacional en su artículo 9.1 establecía que "Podrá someterse a arbitraje toda cuestión relativa a derechos disponibles, sean contractuales, comerciales o litigiosas, o no lo sean, y sean existentes o futuras.". Es decir que se preveía a (diferencia del proyecto aprobado) la Arbitrabilidad en materia civil (sucesiones) y societaria 
tos. Por un lado, las regulaciones expresas en contra a favor y los matices; los temas de Orden Público Internacional (en adelante OPI) y las Normas de Aplicación Inmediata.

Considerando al Arbitraje Laboral, debemos expresar que las disposiciones de la LMU no aplicarían al mismo por dos sentidos. El primero es porque en el caso argentino existen disposiciones específicas sobre este (la ley $14.786^{20}$ para el arbitraje laboral colectivo, y las leyes $14.250^{21}$ y $24.635^{22}$ en materia de arbitraje laboral individual). Asimismo, la LMU establece que se aplicará sin perjuicio de otras disposiciones, y una segunda razón (válida para ambas latitudes) es que la LMU tiene como ámbito de aplicación los "contratos comerciales internacionales" (en el caso uruguayo como afirma Giufra tenemos la discusión sobre si el Arbitraje Laboral aplica en términos del 472.1 y 476 del CGP determinados por los arts. 2153 a 2155 del CC).

Si observamos el arbitraje societario podemos afirmar que, en el caso uruguayo, existe una discusión en torno a su aplicabilidad del art. 150 de la Ley 16.060. Aunque Giufra afirma que "no existe en nuestra legislación societaria ninguna disposición legal expresa que impida el arbitraje" ni tampoco "restricción alguna para la transacción de conflictos societarios ni afectaciones de orden público" (p. 14). En cambio, la ley societaria argentina 19.550 no ha establecido disposición al respecto, por lo cual quedaría sujeta a decisión de las partes. Con relación a la aplicabilidad de la LNA y LNAU puede afirmarse que en primera instancia los aspectos societarios quedarían por fuera de su ámbito de aplicación (interpretación del término comercial).

Otro eslabón en materia de no Arbitrabilidad es la impuesta por el Orden Público (en adelante OP), que en el caso argentino se encuentra regulado en el art. 1649 de su CCCN (no aplicable a ACI, pero de igual manera puede ser considerado fuente de inspiración jurisprudencial). En este sentido se expresó la jurisprudencia, específicamente el caso Francisco Ctibor S.A C. I c. Wall-Mart Argentina SRL s/ordinario. En el mismo se planteó una disputa por la constitución de un Tribunal Arbitral (en adelante TA) por un incumplimiento en torno a la construcción en un predio (contrato de usufructo), en el que Wall-Mart Argentina se había comprometido a construir determinadas instalaciones comerciales y retribuir determinada ganancia a Francisco Ctibor SA C.I. La empresa acusada alegó que esta cuestión no era susceptible de ser sometida a arbitraje puesto que las cuestiones de usufructo y estrictamente pecuniarias eran de Orden Público (en adelante OP) (2152 y 1649 del CCCN) y que según el art. 884 la cuestión tampoco era pasible de ser (a través de la autonomía de la voluntad) sometida a un tribunal arbitral. El tribunal de primera instancia entendió que debía constituir el TA, y que sean los árbitros los que diriman si es se trata de una cuestión subsumible en el marco del OP. La parte afectada alegó que esto era improcedente por la aplicación del principio "iuranovit curia", el cual (como sabemos) supone que el juez se encuentra obligado a conocer todo el derecho y aplicarlo al caso concreto., disposición que no era de recibo puesto que el art

20 La presente ley, establece en su artículo cuarto que si la formula conciliatoria propuesta a las que las que pudieran sugerirse en su reemplazo no fuere admitida el mediador invitara a las partes a someter la cuestión a arbitraje. No admitiendo el ofrecimiento, se dará a publicidad un informe que contendrá la indicación de las causas del conflicto, un resumen de las negociaciones, la fórmula de conciliación propuesta, y la parte que la propuso, la acepto o rechazo

21 El artículo 16 establece la conciliación, la cual una vez resuelta tendrá carácter de cosa juzgada

22 Art. 28.-Si fracasare la instancia de conciliación, el conciliador podrá proponer a las partes que sometan voluntariamente sus discrepancias a un arbitraje, suscribiendo el respectivo compromiso arbitral. 
1654 del CCCN disponía el principio kompetenz-kompetenz. La Corte Nacional expresó que, en definitiva

"En ese orden de ideas, juzgo que el art. 1649 in fine no puede ser interpretado sino teniéndose presente que la tendencia actual observada en la jurisprudencia estatal y arbitral del derecho comparado es la de reducir considerablemente el alcance del orden público en el plano de la Arbitrabilidad de la controversia internacional y su correlativa extensión al plano interno".

En este sentido, se observa una clara restricción por parte de la jurisprudencia argentina en declarar la no Arbitrabilidad por razones de orden público.

Otros dos temas para tener en cuenta son los aspectos de OPI y NAI, los cuales operan también sobre el ACI como se muestra en el siguiente cuadro:

\section{Cuadro I: Materia Arbitrable en Uruguay y Argentina (Orden Público Internacional y Normas de Aplicación Inmediata)}

Normas de Aplicación Inmediata

El árbitro internacional, se encuentra determinado en su actuación por las condiciones que elijan las partes. Esta decisión involucra también el derecho aplicable, es decir, la subsunción del proceso arbitral a un sistema jurídico estadual (generalmente el de la sede), y la normativa extra-etática (reglamento de la institución arbitral).

Esta elección; ¿supone la subsunción de todo el derecho aplicable, o sólo de los elementos elegidos por las partes?

La doctrina argentina señala la posibilidad de que los árbitros "dejen de lado" algunas normas de conflicto sobre $\mathrm{ACl}$, recurriendo a la Autonomía de la Voluntad de las partes.

No obstante, como señalan algunos autores, en esta área tenemos, por ejemplo, las normas de defensa de la competencia, las cuales no pueden dejar de ser consideradas por los árbitros. Estas normas son la ley 25.156 (Argentina) y la ley 18.159 (Uruguay).

Aquí tenemos claramente el tema de arbitraje sobre Marcas o Patentes, en el cual no operan solamente derechos patrimoniales, (Ley 17.011 en Uruguay y 24.481 en Argentina) sino que están en juego derechos morales, los cuales son de orden público.

\section{Orden Público Internacional}

Aquí nos encontramos con una barrera contra la continuidad jurídica de las relaciones, que opera a posteriori de la puesta en funcionamiento del sistema de DIPR.

Si bien las partes pueden elegir el derecho procesal aplicable (como veremos en el capítulo sobre derecho aplicable al $\mathrm{ACl}$ ), tanto la doctrina nacional y como la extranjera señalan que existen notorios límites en este accionar los cuales se encuentran determinados por la vulneración del debido proceso y la libertad de las partes.

Estos elementos se consagran en el art. 5 de la Convención de Nueva York de 1958 y en la CIDIP sobre ACl de 1975 (art. 5).

Este aspecto es contemplado por la LMU, sobre todo en los arts. 18 (igualdad de las partes y defensa de sus derechos) y el art. 15 (imparcialidad de los árbitros).

A pesar de que no existe un análisis cuantitativo exhaustivo y excluyente, la experiencia jurisprudencial muestra que muchos de los recursos judiciales contra el laudo se realizan invocando principios de Orden Público Internacional, sobre todo aplicables a los temas procesales. 


\section{LA AUTONOMÍA DE LA VOLUNTAD}

La autonomía de la voluntad supone un punto de conexión de carácter conductual a través del cual las partes pueden elegir el derecho material aplicable y/o el juez internacional competente a una determinada categoría. En el ámbito uruguayo "las normas que habilitan la autonomía conflictual son de carácter especial con un ámbito de aplicación acotado y material y geográficamente limitado" (Fresnedo, 2015, p.199). Debido a que la posición tradicional ha sido "siempre mayoritariamente contraria a la autonomía de la voluntad, posición esta que ha sido unánimemente seguida por la jurisprudencia y las normas de fuente nacional e internacional" (p. 64. 1994).

En este ultimo la Ley 10.084 a través de la cual se aprobó el apéndice del Código Civil considero en el art. 2403 que "las reglas de competencia legislativa y judicial contenidas en este Título no pueden ser modificadas por la voluntad de las Partes. Esta solo podrá actuar dentro del margen que le confiere la ley competente ${ }^{\prime 23}$. En el caso de las competencias jurisdiccionales en materia de contratos comerciales internacionales tendremos las disposiciones de los arts. 56 del Tratado de Montevideo de Derecho Civil de 1889, el 2401 del Código Civil y el moderno Protocolo de Buenos Aires sobre Jurisdicción en Materia contractual, el cual establece la autonomía de la voluntad restringida y la posibilidad de prorrogar la jurisdicción a tribunales arbitrales.

El anteriormente mencionado art. 2403 es una norma preceptiva sin perjuicio de la discusión de si es de orden público o de orden público internacional. Sin embargo, el mismo no establece una muralla infranqueable contra el paso de la autonomía de la voluntad, sino que más bien restringe su actuación a especialísimas circunstancias, por ejemplo, cuando la ley aplicable para el caso concreto avale la modificación de las competencias legislativas y/o jurisdiccionales. Por su parte, la Ley 19636 permite la prórroga de jurisdicción en los casos establecidos en su ámbito de aplicación solución que no atenta contra el sistema de DIPR uruguayo pues es perfectamente armonizable con el art. 2403.

Considerando el ordenamiento jurídico argentino, debemos destacar que se parte de una posición favorable con un "fundamento legal en los artículos 14 y 19 de la constitución argentina, que amparan la libertad de las acciones humanas" (Gastaldi op cit. Fresnedo, 1994, p.50). En cuanto a s su regulación expresa, en dicho país observamos que se consagra una autonomía de la voluntad amplia con algunas limitaciones. Las reglas concernientes a competencias jurisdiccionales se encuentran subsumidas en el Protocolo de Buenos Aires (restringida a un espacio geográfico) y en el art. $2650^{24}$ del CCCN, sumado a las disposiciones en materia de autonomía de la voluntad contenidas en el art. 2651 del mismo

23 "El informe de la Comisión de Códigos de la Cámara de representantes reafirma esta idea y agrega que la competencia internacional se determina por razones superiores a la voluntad de las partes comprometidas en una relación jurídica y que ellas pueden, dentro del margen que les otorgue la ley competente, fijar con amplia autonomía, la extensión del margen de libertad que les otorga la ley competente, fiar con amplia autonomía, la extensión y alcance de sus obligaciones, pero no pueden variar el curso de la competencias internacionales que son fundamentalmente de orden público, porque afectan en su faz legislativa o judicial la soberanía del país en que se localiza la relación jurídica y están por lo tanto por encima de sus individuales voluntades" (op. cit. Fresnedo, 1994, p.67).

24 El Cual establece que, no existiendo acuerdo valido de elección de foro, con competentes para conocer en las acciones resultantes del contrato, a juicio del actor 
código. Por lo que la ley 24744 sobre ACI aprobada por Argentina se subsume dentro de la consideración acuerdo de elección de foro válido establecido por el 2650 de su CCCN.

\section{LAS REGLAS DE INTERPRETACIÓN}

La interpretación "es una investigación dirigida a determinar el verdadero significado de una norma jurídica" (Talice, 1974 p.117). (Talice, 1974, p.117). La teoría del derecho discute si este proceso cognitivo debe realizarse en cualquier circunstancia o sólo ante vaguedad, ambigüedad o marginalidad de la norma y/o conflicto entre dos "leyes" con jerarquía diferente. No obstante, se trata de discusiones que escapan al objeto de esta investigación. Podemos distinguir que esta tarea posee dos elementos; el literal gramatical y el teleológico. Este último se basa en aspectos de ratio Legis, sistemáticos, políticos, sociales, históricos y comparativos., obteniendo resultados declarativos, restrictivos, extensivos y progresistas. (Talice, 1974).

La labor interpretativa de las normas de DIRP debe hacerse teniendo en cuenta su especial naturaleza, por lo cual será necesario separar distinguir entre el supuesto regulado ${ }^{25} \mathrm{y}$ la disposición sobre dicho supuesto regulado Esto implica considerar primero la aplicabilidad de la norma, la calificación, y luego establecer las condiciones en las que se aplicará. Y en el caso de las normas de conflicto interpretaciones sobre la categoría y el punto de conexión $\left.{ }^{26}\right)$. El sistema jurídico uruguayo prevé en su Título Preliminar de las Leyes $^{27}$ (incorporado en el Código Civil) las líneas generales en torno a la interpretación e integración (arts. 15 al 17) las cuales se aplicarán a todo el derecho civil y comercial, nacional e internacional. En el caso del derecho argentino, su Código Civil y Comercial lo establece en el Art 2, teniendo una solución similar.

El DIPR posee la función específica de integrar diversos tipos de normas y de sistemas jurídicos (Talice, 1974, p.124 y sigs.), bajo el principio de contextualidad (expresado por la Prof. Fresnedo). Es justamente esa especificidad la que hace necesario generar normas concretas en materia de interpretación e integración, tendencia que está presente en diversas ramas del derecho. Por ejemplo, en lo que refiere al proceso penal, el nuevo CPP uruguayo consagra criterios sobre esta temática en su art. 14 (los cuales se aplican en materia de Cooperación Penal Internacional y Extradición ${ }^{28}$ ). En materia de Contratación Internacional, nuestro sistema de DIPR adoptó la Convención de Viena del 1980, la cual establece criterios específicos en dicha materia, adoptando los principios de ex bona fide, buen hombre de negocios y razonabilidad como elementos clave).

\footnotetext{
25 Talice distingue cuatro grandes teorías para la interpretación del supuesto normativo; por un lado, la lex fori y la exegética que serían técnicas intra-ordine y por el otro lado lex causae o comparatista de Rabel que son técnicas extra-ordine (p. 127 y sigs.). Esto sería a nivel general, en términos particulares tenemos el método funcional para "resolver el conflicto de calificaciones en el DIPR" analizado por el profesor Lorenzo Idiarte.

26 Aquí debemos distinguir si el punto de conexión es factico o jurídico. En el último caso sería necesario recurrir a algunas técnicas de interpretación para determinar que se entiende por este, y por lo tanto cual es el derecho sustantivo aplicable.

27 El mismo conserva la estructura dada por la Ley 917 de 1868.

28 Sin embargo, no debemos desconocer a importancia de los criterios generales de Interpretación, ya que por ejemplo el proyecto de ley sobre DIPr uruguayo contempla en su art. 1 que los criterios de interpretación serán los dados por el título preliminar de las leyes del CC.
} 
De conformidad con lo dispuesto por la UNCITRAL, las leyes de Argentina y Uruguay destacan el "origen internacional" del ACI (principio teleológico), diferenciándolo así del Arbitraje Interno. Por su parte, se reafirma la promoción de la uniformidad. Esto implica que ante un diferendo no exista la incertidumbre sobre cuál será el derecho aplicable al caso. En materia de integración, se adopta una solución idéntica a la dispuesta por la Convención de Viena, recurriendo a los principios generales que inspiraron a la presente ley, teniéndose en cuenta el carácter internacional, y la intención teleológica de dar continuidad jurídica al negocio ${ }^{29}$.

Hay que destacar que antes de la aprobación de estos instrumentos jurídicos, era posible encontrarnos con muchos supuestos no regulados que debían ser subsanados a través de complejos trabajos de integración. Finalmente, debe señalarse que, amén de los principios contenidos en la LNAU, los mismos coexistirán con los arts.15 a 17 del CC, por su especial característica presentada al principio de este apartado.

\section{EL DERECHO APLICABLE A LOS DISTINTOS ASPECTOS DEL ARBITRAJE COMERCIAL INTERNACIONAL}

El mundo anglosajón distingue el derecho aplicable al ACI en torno a cuatro elementos: 1) la ley aplicable a la sustancia de la controversia de las partes"; 2) la ley aplicable al acuerdo de arbitraje; 3) la ley procesal aplicable a los procedimientos arbitrales; y 4) las reglas de elección de leyes aplicables en el arbitraje internacional (Born, 2011). Por su parte, la doctrina uruguaya habla del derecho aplicable en dos sentidos; por un lado, el derecho aplicable al fondo del litigio, o sea a la controversia que se pretende resolver y por otro lado al procedimiento arbitral" (Santos, 2018 p. 97).

El primer aspecto para destacar es el tema del derecho aplicable al procedimiento. Sobre este punto debe partirse mencionando el art. 19 de la LNAU y art.29 de la LNA, en los cuales se consagran dos principios. En el primero de ellos se establece que "las partes tendrán libertad para convenir el procedimiento a que se haya de ajustar el tribunal arbitral en sus actuaciones". Debe comprenderse, como señalan Carbonneau y Gary Born, que esta elección de derecho procesal se refiere a adoptar las percepciones objetivas y subjetivas, jurídicas y jurisprudenciales que ese país tiene sobre el ACI, adoptando la universalidad en torno al instituto y no sólo a los aspectos meramente procedimentales, excluyendo de esto los reglamentos procesales de las instituciones arbitrales de dicho país, para lo cual entiendo que se debería realizar una sumisión voluntaria expresa a dichas disposiciones salvo que estén recogidas por la jurisprudencia.

A falta de elección se dispone que "el tribunal arbitral podrá, con sujeción a lo dispuesto en la presente ley, dirigir el arbitraje del modo que considere apropiado" (LNAU). El CPCCN ya establecía algo similar en sus arts. 751 y 769, si bien con una redacción distinta. Este principio no es de carácter absoluto, sino que se encuentra restringido por los principios

29 Es interesante destacar que ambas leyes se incorporan al DIPR de fuente etático, al ser leyes surgidas de los poderes legislativos sujetas a todas las modificaciones que el Legislador considere prudente. Ahora bien, debemos pensar hasta qué punto influye que dicha norma sea tomada de un "modelo" producido por la UNCITRAL, otorgándole un valor subjetivo de que no debería ser modificada salvo que lo sea la ley modelo. Por supuesto estos son solo valoraciones subjetivas no respondiendo a ningún criterio jurídico. 
de OP y OPI). En esta elección pueden considerarse claramente dos opciones. Una de ellas es elegir la ley del asiento del arbitraje y otra una extranjera. Como señala la doctrina francesa, la elección de una loi de l'arbitrge supone una revaloración de la propia existencia, y validez del ACI, así como aspectos de valoración de las pruebas, estructura del procedimiento y la propia eficacia extraterritorial del laudo (recordando que quizás tengamos una ley internacionalmente aplicable al contrato, otra para el acuerdo arbitral y una tercera para los aspectos procesales del ACI), (Born, 2011).

En segundo lugar, vamos a considerar los elementos que conciernen a las normas aplicables a los aspectos de fondo del litigio. Los mismos se encuentran subsumidos en el art. 28 de la LNAU y el de la LNA. La primera opción que presentan ambos es que "el tribunal decidirá el litigio de conformidad con las normas de Derecho elegidas por las partes como aplicables al fondo del litigio". En este sentido, el Dr. Talice comenta que dicha elección está condicionada (al igual que el derecho aplicable al procedimiento) por la existencia de normas de policía y disposiciones de OPI $(2019$, p.65) e incluso temas constitucionales y de debido proceso. Con respecto a esta última cuestión observamos las disposiciones del art.18 de la LAU y el de la LNA, los cuales disponen que "Deberá tratarse a las partes con igualdad y darse a cada una de ellas plena oportunidad de hacer valer sus derechos".

Como señala el autor, la libertad para elegir el corpus jurídico aplicable al fondo, ve la luz por vez primera al sancionarse "la convención europea sobre ACI, la cual consagra por vez primera la libertad de las partes para elegir el derecho aplicable y la del árbitro para recurrir en su defecto, a la regla de conflicto que juzgue apropiada al caso litigioso" (p. 65).

En cuanto a los medios por los cuales se manifiesta la expresión de voluntad para elegir el derecho aplicable al fondo del litigio, Talice, Gary Born y Carboneau coinciden en que puede realizarse a través del propio acuerdo arbitral el cual, de conformidad con todo el sistema jurídico de ACI, tendrá que ser por escrito.

Asimismo, hay que considerar qué se entiende por "reglas de derecho". Según la nota explicativa de la LMU, se debe entender por estas que:

Se "referencia a la elección de las "normas de derecho" y no a la "ley", la Ley Modelo brinda a las partes una gama de opciones más amplia en lo tocante a la indicación de la ley aplicable al fondo del litigio. Por ejemplo, podrán elegir de común acuerdo por normas de derecho elaboradas por un organismo internacional pero no incorporadas aún a ningún ordenamiento jurídico nacional. Las partes también podrán determinar directamente que el derecho sustantivo que ha de regir el arbitraje sea un instrumento como la Convención de las Naciones Unidas sobre los Contratos de Compraventa Internacional de Mercaderías, sin necesidad de remitirse a la legislación interna de ningún Estado parte en esa Convención" (UNCITRAL, p.37).

En el caso específico de la LNA se entiende que de conformidad con su art. 15 (el cual establece que se entenderá que el acuerdo de arbitraje es escrito cuando quede constancia de su contenido en cualquier forma), se abriría la puerta para concebir la elección de derecho de fondo de forma tácita. 
En cuanto a que qué sector del derecho fue el elegido por las partes, se debe expresar que el mismo hace referencia a la ley etática, descartándose las disposiciones de las normas de conflicto (para evitar la remisión a otro estado y las posibilidades de reenvío). Como señala Rubén Santos, este numeral no debe ser interpretado como la elección de un derecho netamente estadual, ya que podrían elegirse reglas no gubernamentales, es decir, las establecidas por los operadores del comercio internacional (lex mercatoria). ${ }^{30}$ Por su parte, las leyes de arbitraje objeto de estudio disponen que en los casos en que las partes no hayan indicado el derecho aplicable, el mismo será escogido por el tribunal arbitral conforme a los criterios que estime conveniente. Dejando claro que el propósito de ambas leyes no es que los tribunales decidan esto, más bien todo lo contrario, el espíritu es que las partes (en el ejercicio de la autonomía de la voluntad) establezcan el derecho aplicable al fondo del litigio.

\section{LA CLÁUSULA ARBITRAL O COMPROMISORIA}

La Cláusula Arbitral o Acuerdo arbitral es ante todo una toma de decisión sobre la cual se produce una prórroga de jurisdicción a favor de un tribunal arbitral de naturaleza privada, utilizando la conexión autonómica ya mencionada. La distinción entre Cláusula Arbitral y Compromiso Arbitral ${ }^{31}$ fue superada por las disposiciones de las distintas fuentes de DIPR a los efectos de evitar problemas de aplicabilidad. Las dos grandes características que definen la validez del acuerdo arbitral, según las normas de fuente etático y plurietática son; la celebración por escrito y el consentimiento de las partes ${ }^{32}$.

Para que el acuerdo arbitral adquiera validez y eficacia, deben cumplirse determinados requisitos en cuanto a las formas. En el ámbito supranacional la Convención de Nueva York en su art. 2 inc. 2 "Define en forma contundente e inequívoca lo que se entiende por acuerdo por escrito" estableciendo que la "Expresión acuerdo escrito denotará una cláusula compromisoria incluida en un contrato o) un compromiso firmados por las partes o contenidos en un canje de cartas o telegramas." Expresando que es "una norma material especial para el tráfico externo, de origen convencional y de carácter imperativo". (Noodt Taquela, 2000, p. 122), y agregando además que intenta "evitar la aplicación de una técnica conflictual". En el mismo sentido se expresa la CIDIP-I sobre ACI y los acuerdos del MERCOSUR (art. 6).

La fuente nacional contenida en el CGP establece en su art. 473.2 que será por escrito "so pena de nulidad". Incluso en su art.477 dispone la obligatoriedad de escritura pública para su validez, lo cual no se condice con el DCI y sus modalidades. El art. 739 del CPCCN determina lo mismo que el uruguayo, pero permite también la celebración mediante escritura privada. Cómo nos dice Noodt Taquela, "si el acuerdo arbitral es el

\footnotetext{
30 Talice en este aspecto comenta que el termino ley (establecido por el art 28) designa "las normas pertenecientes al sistema jurídico etático que las partes pueden elegir en un ACI para regular el fondo del litigio... ejerciendo esta libertad, las partes pueden elegir una ley con o sin vínculo con el objeto del litigio, pueden también designar varias leyes siguiendo la técnica del depesage, elegir" una ley neutra, congelada o acumuladora. Si bien es ampliamente admitido la utilización de la lex mercatoria tal como afirma Rubén Santos.

31 La Cláusula Arbitral, se realiza antes de que surja un litigio (en el contrato) y el Compromiso arbitral. El mismo tiene "cronológicamente una existencia posterior a la aparición de la diferencia entre las partes" (Rubén Santos 2001 p. 53).

32 En materia del perfeccionamiento del acuerdo arbitral tenemos por un lado las disposiciones generales establecidas por el Art 42 del TDCIM de 1940, y en materia especifica el art 6 de los acuerdos del MERCOSUR sobre ACI.
} 
fundamento para excluir la actuación de los tribunales estatales y abrir la jurisdicción privada, la voluntad de las partes debe expresarse de un modo indudable" (p.123).Esta "insistencia" por el acuerdo escrito y formado por las partes, se debe a que es la única manera en que se puede "exteriorizar el consentimiento de las partes de someterse a una justicia privada"(Sandler Obregon, 2006)..$^{33}$

Hay que destacar el tema de la autonomía de la cláusula arbitral con respecto al contrato que dio origen a la controversia. La misma significa "que la inexistencia o invalidez del contrato no implica necesariamente la nulidad de la convención arbitral" 34 (Noodt Taquela, 2000, p.128) y fue regulada en el Art II de la Convención de Nueva York, art. 3 de la CIDIP-I sobre ACI y los arts. 5 y 18 de los acuerdos del MERCOSUR.

La LMU había regulado al acuerdo arbitral en 1985 de conformidad con las disposiciones de la Convención de Nueva York en tanto que se mantenía la exigencia por escrito. En este sentido, según expresa la propia UNCITRAL en su nota explicativa, "los profesionales del arbitraje han señalado que, en varias situaciones, la elaboración de un documento por escrito resulta imposible o poco práctica". A este respecto, la reforma del 2006 de la LMU modificó el art. 7 estableciendo dos opciones. La primera de ellas optaba por mantenerlos criterios de 1985 (en el cual se mantenían las disposiciones en torno a la forma) y la segunda opción no hace mención a las formas.

La LNAU en su art. 7 se inclina por la primera opción (la de 1985), aunque como comentan Ricardo Olivera García y Laura Chalar Sanz, "si bien adopta (la fórmula tradicional), en cuanto a que se entiende por acuerdo escrito, usa una redacción más ajironada que la Ley Modelo". Por su parte, la LNA flexibiliza esta cuestión al establecer que "El acuerdo de arbitraje deberá constar por escrito. Se entenderá que el acuerdo de arbitraje es escrito cuando quede constancia de su contenido en cualquier forma".

A este respecto, señalan Mistelis y Kroll que "no existiría razón para someter a los acuerdos de arbitraje a requisitos formales más estrictos que otros tipos de contratos. Ya que no es considerado una peligrosa renuncia a derechos sustanciales" (op. cit. Olivera García Chalar Sanz, 2018, p.38). Con respecto al derecho aplicable a la cláusula arbitral, según la CIDIP-I sobre ACI se regirá por la ley elegida por las partes o la ley sede del tribunal arbitral, y asimismo tenemos las normas materiales de los acuerdos del MERCOSUR, que regulan la validez formal e intrínseca del acuerdo. En torno a la primera, expresa que se regulará por el derecho del lugar de celebración (a falta de cumplimiento de este punto de conexión, se aplicará el núm. 5 del art. 6). En cuanto a la validez intrínseca, la misma se regulará por el derecho del lugar del arbitraje.

33 La doctrina anglosajona establece que este requisito por escrito tiene como fin "asegurar que las partes hayan efectivamente pactado el arbitraje. Dado que el acuerdo arbitral puede llevar a la renuncia de las partes de su derecho constitucional de ver sus controversias ante los tribunales, la forma escrita busca evitar que el acuerdo pase desapercibido. En segundo lugar, la escritura brinda un registro el acuerdo ue ayuda a probar la existencia y contenido del acuerdo arbitral en ulteriores procedimientos" (Gary Born 2011. P 659)

34 Esta autonomía se funda en que la Clausula arbitral no es una cláusula contractual común, puesto que "tiene por única función y por finalidad extraer del conocimiento de la jurisdicción ordinaria las eventuales controversias que se susciten entre las partes... afiarmandose incluso que es jerárquicamente superior al contrato" Además se expresa que la misma posee condiciones diferentes de validez y eficacia con respecto al contrato principal, y fuentes aplicables diferentes 


\section{CONFORMACIÓN DEL TRIBUNAL ARBITRAL}

Una vez que ha surgido el litigio, se debe determinar la cantidad de árbitros que compondrán el tribunal arbitral, así como el idioma y sede, elementos que se desprenden del acuerdo arbitral. Como nos dice Mateo Veiras Mezzera, "A efectos de garantizar la imparcialidad, disponibilidad e independencia de los árbitros, las instituciones arbitrales exigen a los árbitros designados firmar declaraciones al respecto" (p.66). Una vez conformado el Tribunal Arbitral, será el árbitro quien desempeñe la función jurisdiccional.

El caso 943 de la ley expresa que "los árbitros tienen la calidad de funcionarios judiciales desde que el juicio arbitral ha sido creado como una jurisdicción especial, que les confiere la potestad de juzgar y hacer ejecutar lo juzgado, debiendo las sentencias ser obedecidas cómo si las mismas emanaran de los jueces ordinarios". (Rubén Santos, 2002, p. 97). El CGP uruguayo establece un capítulo a la constitución del tribunal arbitral (arts. 480 al 487), disponiendo que serán 3 o 5 árbitros ${ }^{35}$, mayores de 28 años, los que conformarán el TA, los cuales designarán al árbitro sustanciador (art. 482), regulando además los motivos para el reemplazo, recusación y remoción de estos. El CPCCN lo regulaba en los arts.743 al 745, siendo una regulación similar a la uruguaya con algunas variantes.

En cuanto a la normativa de DIPR supranacional, tenemos a la Convención de Nueva York de 1958 así como la CIDIP Panamá de 1975 que poco expresan en torno a los árbitros. Es la normativa del MERCOSUR la que se expresa mayormente sobre el tema (arts. 16 y 17), aunque estos son aplicables únicamente a los países miembros. La ley nacional de ACI tanto en Argentina como en Uruguay replicaron de forma casi idéntica que la ley modelo los aspectos de la elección de los árbitros en los arts. 10 al 15, a través de la cual se consagra la autonomía de la voluntad en torno al proceso de elección de los árbitros restando la libertad de las partes. No obstante, en los casos en que las partes "no hayan hecho uso de esa libertad se deberán establecer normas supletorias que" garanticen la eficacia y que se "dirima la controversia" (UNCITRAL,2006).

En relación con la recusación de los árbitros, la LNA establece, diferencia de la LNAU y la LMU, dos "ejemplos" de causales de recusación, a saber:

“a) Como patrocinante o representante de una de las partes, independientemente de la cuestión en debate, o b) Con la misma causa o con el mismo objeto, como patrocinante o representante de un tercero". "El supuesto incorporado por la ley argentina sin duda tiene su origen en algunos casos en que la Argentina era demandada ante la CIADI en los que las recusaciones de ciertos árbitros fueron descartadas (Rivera, 2018, p.197).

\section{COMPETENCIA DEL TRIBUNAL ARBITRAL}

Una vez comenzado el proceso arbitral, debemos tener en cuenta cuál es el alcance de la función de jurisdictio que tienen los árbitros. En torno a esto, siguiendo la lógica del proceso, podemos referirnos primeramente a la posibilidad en la que se cuestione la

35 En este sentido se expresa el artículo 5 del reglamento de la CIAC, al establecer que si las partes no han convenido nada en contrario se nombraran 3 árbitros. Lo mismo establece el reglamento de ACI de la ICC (art 8) 
competencia de los Tribunales Arbitrales, teniendo la posibilidad de ellos mismos examinar su competencia sin intervención de las autoridades jurisdiccionales estatales. Más adelante se analizará que facultades especificas poseen estos y cuál es su interacción con los jueces estatales para el cumplimiento de estas.

Estos elementos se encuentran regulados en los arts. 16 y 17 de LNAU y 35 a 37 de LNA, destacándose que ambos proyectos consagran el principio "Kompetenz-Kompetenz y de la separabilidad o autonomía de la cláusula compromisoria." (UNCITRAL,2006). Según la doctrina alemana, esta cláusula significa que 1) las partes no se tienen que "poner en contacto" con un tribunal estatal y otro organismo para analizar la competencia del Tribunal Arbitral y 2) que este derecho no será razón para desconocer el laudo emitido por estos (Ilja Alexandrov, 2002, p.35).

No obstante, según el autor, para que este elemento no se utilice como un medio para retrasar el proceso, el TA podrá analizar esta competencia en paralelo que avanza el proceso arbitral. Hay que destacar que la cláusula establecida por la LMU se diferencia de lo que disponen los acuerdos del MERCOSUR, a raíz de que permite la excepción por haber excedido su mandato el tribunal arbitral e incluso podrá recurrir a los tribunales estatales ante la declaración de competencia de dicho TA (art. 16 inc. 2 y 3 de la LMUU y arts. 36 y 37 de la LMUA). El segundo aspecto por destacar es la autonomía de dicha cláusula con respecto del contrato internacional en el que está inserto. Esta "asegura que las eventuales impugnaciones de nulidad o invalidez del contrato principal no impacten sobre la cláusula, por ende sobre la jurisdicción arbitral" (Olivera García, 2019, p.39-40). De las leyes aprobadas, así como los comentarios de la UNCITRAL, se desprende que esto no se hará sin un control judicial, siendo analizado (además) como una cuestión previa.

Esta última cuestión debe ser tenida muy en cuenta, ya que un aspecto fundamental, es la autonomía de la cláusula arbitral (con respecto del contrato) debido a que la nulidad del contrato conlleva la de esta, y por ende del propio ACI. El problema se agravaba al no existir en los ordenamientos jurídicos uruguayo y argentino normas específicas en torno a esto. A lo sumo en el CGP existía la solución del art. $491^{36}$. Por su parte, Gustavo Parodi menciona algunas posiciones doctrinarias como la del profesor Véscovi, el cual expresaba que "la cláusula arbitral excluye la jurisdicción común y obliga a resolver las contiendas en la jurisdicción arbitral (art. $475 \mathrm{del} \mathrm{CGP).} \mathrm{Tanto} \mathrm{lo} \mathrm{que} \mathrm{es} \mathrm{la} \mathrm{doctrina} \mathrm{entiende} \mathrm{que} \mathrm{es}$ válida, aun cuando el contrato, por otras estipulaciones sea nulo". Más allá de esto y de todos los argumentos lógicos que se podían dar, la inexistencia de una solución en el derecho positivo hacía que este tema fuera una caminata por arenas movedizas.

Un segundo conjunto de competencias que es necesario mencionar son aquellas referidas a la posibilidad de efectuar medidas cautelares, cuya finalidad es "prevenir el daño derivado del retardo de una decisión jurisdiccional definitiva asegurando la eficacia de la misma, se dan "previamente a un proceso o durante éste, para evitar que el demandado haga ineficaz sus efectos prácticos o los burle mediante maniobras más o menos ilícitas"(Tellechea, 2002).Cómo nos dice Véscovi, para que las autoridades jurisdiccionales ordenen la realización de

36 Cuestiones conexas. - Constituido el Tribunal Arbitral, se entenderán sometidas a él todas las cuestiones conexas con lo principal que surjan en el curso de este. En este caso, dichas cuestiones se tramitarán por el procedimiento que las partes convengan y, en su defecto, por el señalado para los incidentes. 
una medida cautelar "deben darse tres principios; Fono bono iuris, periculum in mora y contracautela" (2002, p. 134). Las mismas, en tanto establecen una profunda afectación de derechos (forma temporal) constituyen una facultad exclusiva de las autoridades jurisdiccionales estatales. En el caso que el TA deba requerir la realización de esta, bastará con un pedido dentro del derecho "procesal" ordinario sujeto a las disposiciones de los códigos procedimentales civiles. En los casos donde se requiera la realización de dicho acto procesal en un estado distinto a la sede arbitral será necesario recurrir a las normas de derecho procesal civil internacional, ya sea supranacional o nacional.

El derecho, tanto de fuente supranacional como nacional, tradicionalmente no contempló la posibilidad de que las autoridades arbitrales dispusieran su realización, ${ }^{37}$ pero el art. 19 de los protocolos del MERCOSUR estableció la posibilidad de que las medidas cautelares puedan ser dictadas por el tribunal arbitral. No obstante, agrega también que podrán ser por la autoridad judicial competente. Sin embargo, en última instancia el diligenciamiento se realizará ante un juez, que se lo enviará al juez requerido para que efectivice (en virtud de ello, aplicará el Protocolo de Ouro Preto para los aspectos generales). Fuera de este ámbito, hasta ahora se tenía que recurrir al ámbito judicial y proceder de conformidad (en caso de que fuera internacional) con las normas específicas de las medidas cautelares (Ouro Preto, Interamericana o los códigos procedimentales argentino o uruguayo).

Con la aprobación de las LMU en ambos países, tenemos una norma similar a la establecida por dicha Organización Internacional para todos los casos (art. 17 en la LNAU y arts. 36 a 60 de la LNA) con las ventajas que eso conlleva (que el tribunal arbitral decida los aspectos de fondo de la medida cautelar y el tribunal jurisdiccional proceda a los aspectos de diligenciamiento). Vale destacar que la doctrina argentina con Caivano y Noodt Taquela a la cabeza comentan que es posible que el TA disponga medidas cautelares no coercitivas, las cuales las partes las cumplan por motus propio.

\section{INTERVENCIÓN DE TERCEROS EN EL ARBITRAJE COMER- CIAL INTERNACIONAL}

No debemos dejar de mencionar la posibilidad de la alteración del derecho aplicable al fondo del litigio por la intervención de terceros en el proceso. La primera discusión se da en torno a las condiciones en las que se da la mencionada intervención ${ }^{[1]}$. Las doctrinas suiza y francesa distinguen dos tipos; voluntario y forzoso. En el primer caso, Xavier Fevbre Bulle expresa que el arbitraje voluntario se da cuando una parte que no pertenecía al acuerdo original se ve subsumida dentro del caso (ejemplo: caso de arbitraje de construcción cuando el contratista general que es demandado, demanda a un subcontratista), también llamado tercerías ${ }^{38}$. o en los casos de intervenciones técnicas.

37 En el caso argentino el art 753 de su CPCCN establece que "Los árbitros no podrán decretar medidas compulsorias, ni de ejecución. Deberán requerirlas al juez y este deberá prestar el auxilio de su jurisdicción para la mas rápida y eficaz sustanciación del proceso arbitral.". Y estas disposiciones se encuentran en muchas provincias. Misiones en el 753, Rio negro 753, Buenos Aires 791, Tierra del Fuego 728, Chubut 753 etc.

38 La doctrina colombiana expresa que "Las tercerías (simple) son la intervención de un tercero en el cual ese tercero formula su propia pretensión la cual puede ser oponible o incompatible con la del demandante" (Duarte y Mendoza, 2016 p. 40). A su vez Hernando Devis Echandia (citado Duarte y Mendoza, 2016 p.41) expresa que en la misma "Se introduce un nuevo litigio 
En el segundo supuesto tendríamos intervenciones forzosas en arbitrajes por derecho de la competencia (vulneran un interés de la comunidad), o en los casos inversor-Estado (no objeto de esta investigación) también por temas de denunciado en pleito, integración del contradictorio entre otros. La cuestión aquí es que las leyes sobre ACI aprobadas por Uruguay y Argentina no especifican estas cuestiones, por lo cual las mismas quedarán sujetas a lo dispuesto por los reglamentos de las instituciones arbitrales a las que se sometan las partes, o a lo convenido por estas en el caso de arbitrajes ad hoc. Ahora bien, es necesario destacar la posibilidad de una intervención estadual preceptiva considerando las normas de aplicación inmediata y el OPI (como vimos en capítulos anteriores).

Actualmente, la doctrina anglosajona y europeo continental, está discutiendo, en materia de intervención de terceros en el ACI, la extensibilidad de la cláusula arbitral hacia terceros no signatarios (aspecto que escapa el objeto de esta investigación).

\section{IMPUGNACIÓN Y NULIDAD DEL LAUDO ARBITRAL}

En este apartado analizaremos las formas que se tiene para impugnar, es decir, negar y anular el fallo emitido por el tribunal arbitral. Esta se da antes de que opere la "eficacia extraterritorial" A consecuencia este recurso tiene como finalidad invalidar el laudo. Lo que tendremos después son aquellos elementos que niegan la continuidad jurídica, sin embargo, no atacan su validez internacional (como el principio del OPI ${ }^{39}$ ). Este recurso es el que se interpone ante la res iudicata (res arbitrata, o "autorité de chosejudgee ") ${ }^{40}$ puesto que en materia arbitral no existen "tribunales de apelaciones" ni "recurso de casación". Debido a que la irrecurribilidad es uno de los principios del instituto.

Por esta razón, aquí se descargan todas las baterías para poner fin a dicha continuidad jurídica. Ya que "un tribunal competente para resolver sobre la petición del laudo (ante una posible denegación de continuidad jurídica), debe ceñirse estrictamente al análisis de las causales de nulidad" (Elina Mereminskaya 2006) para que esto no se convierta en un "tribunal de apelaciones por la vía de los hechos".

Sumado a que los recursos de impugnación del laudo a disposición de las partes difieren ampliamente de un ordenamiento a otro. Las disposiciones de la UNCITRAL (a través de la ley modelo), vienen a coadyuvar al proceso de unificación de soluciones del DIPR. Generando recursos claros y concisos en dicha materia. Tanto la LNA y la LNAU recogen las disposiciones de la ley modelo casi a texto literal, estableciendo dos grandes vertientes; 1) Los que han de ser probados por la parte que interpone la petición o 2) que el acuerdo no sea válido, que entre otras cosas puede ser que la autoridad competente que violente el OPI (la mención de OPI es una innovación técnica de Uruguay y Argentina).

al proceso, pues la Litis, limitada a la pretensión del demandante, se extiende a una nueva formulada por el tercero." En la tercería excluyente "Se presenta cuando el tercero interviniente formula su pretensión contra el demandante, para que se le reconozca un mejor derecho, y contra el demandado, a fin de que se le condene a satisfacerlo" (Ídem. p. 42)

39 Podemos decir que a la hora de aplicar el derecho extranjero lo hacemos "como un derecho", teniendo en cuenta el principio iuranovit curia. Esta aplicación tiene algunas excepciones entre las que se encuentra el OPI el cual niega la continuidad jurídica de las relaciones atendiendo a los principios sobre el cual el Estado asienta su individualidad jurídica.

40 Cosa Juzgada: Como nos dice Francisco Prol aquí podemos dar la discusión de cuál es la ley aplicable a la cosa juzgada. Si la lex fori del que rigió el primer procedimiento, la del segundo procedimiento o la ley sustantiva a las que las partes sometieron el arbitraje. 
Las causales sobre las cuales las partes fundan los argumentos jurídicos para la nulidad del laudo arbitral se encuentran en consonancia con aquellos elementos que se interponen ante las autoridades jurisdiccionales para frenar la eficacia extraterritorial de los laudos, pero también de las sentencias. En definitiva, estos principios consagrados en el art. 39 de la LNAU y art. 99 y ss de la LNA).

Los principales argumentos versarán sobre los siguientes temas, a saber: La incapacidad de las partes y la no Arbitrabilidad del litigio (ya analizado), violaciones a los principios generales del derecho procesal, tales como la inexistencia de notificaciones debidamente realizadas, la designación de los árbitros o no haber podido hacer valer sus derechos. En torno a los mencionados temas procesales, cabe destacar la sentencia definitiva i74/2011 del tribunal de apelaciones en lo civil, que pedía la anulación del laudo arbitral atendiendo a los principios de OPI, la falta de garantías procesales y la falta de parcialidad de los árbitros, pretensión que fue denegada ya que entre otras cosas (cómo la falta de pruebas y competencia) se estaba pidiendo la nulidad cuando en si el tribunal podrá denegar su ejecución ${ }^{41}$.

En cuanto a los temas procedimentales, tenemos que La petición de nulidad deberá formularse dentro de los treinta (30) días contados desde la fecha de la recepción del laudo o, si la petición se ha hecho con arreglo al Capitulo 6 del Título VII de la presente ley, desde la fecha en que esa petición haya sido resuelta por el tribunal arbitral. (art 100 LNA)

\section{RECONOCIMIENTO Y EJECUCIÓN DEL ACI}

En este apartado observamos el proceso a través del cual ya se ha establecido el laudo arbitral y se han agotado las instancias de oposición por nulidad. Por lo tanto, es el momento de su eficacia extraterritorial ${ }^{42}$. El Marco Jurídico en esta área estará dado por los arts. 18 a 22 del Protocolo del Valle de las Leñas, los Acuerdos del MERCOSUR sobre ACI (que remite en su art. 23 a la normativa antes mencionada), el art. 5 de la Convención de Nueva York de 1958 y el art. 5 de la CIDIP-I sobre ACI.

En el sistema de DIPR etático, Argentina tenía las disposiciones de su CPCC, el cual lo regulaba en su art. 519 bis que a su vez nos remite a los arts. 517 y 537. Derogado de forma expresa por la LNA aplicándose los arts. 102 y ss. La normativa uruguaya de fuente nacional no poseía regulación; el art. 539 del CGP solo se aplicaba a las sentencias $^{43}$. La aprobación de la LNAU significó una innovación, al establecer por primera vez criterios jurídicos para el reconocimiento extraterritorial de los laudos arbitrales

41 También reconoce que admitiendo que se trata de cuestiones distintas (validez y ejecutabilidad de un laudo) se ha señalado, con razón, una coincidencia básica entre las circunstancias que invalidan un laudo y las que impiden su reconocimiento y ejecución, de modo que podría declararse la nulidad del laudo cuando se verifica alguna de las condiciones que obstan su reconocimiento y lo hacen inejecutable

42 Las autoridades jurisdiccionales han equiparo los laudos arbitrales al tratamiento otorgado a las sentencias emitidas por autoridades estaduales, de modo que será menester considerar brevemente el proceso de eficacia extraterritorial de las mismas. Este procedimiento se le denomina exequatur, y establece que la misma deberá ser presentada ante la suprema corte de justicia (la cual controlará los requisitos formales, documentales y procesales) Posteriormente se escucha al ministerio público y se emitirá el fallo. El cual podrá reconocerla o no.

43 En principio se da continuidad jurídica a aquellas sentencias que sean definitivas y en materia civil y comercial. En el caso de los Laudos Arbitrales estos están sujetos a los requisitos formales, documentales, procesales y de OPI 
(arts. 39 y 41 y art. 104 de la LNA). A grandes rasgos, la LNA y la LNAU establecen, en concordancia con la normativa mencionada supra, cinco criterios para la denegación del laudo, a saber:

Capacidad de las Partes para celebrar el acuerdo: Se trata de una categoría autónoma en los DIPR de ambos países, subsumible en el art. 1 del Tratado de Montevideo de 1889 y 1949, los arts. 2393 del CC y 2616 del CCCN argentino (regulado por la ley del domicilio, y este debe ser interpretado in ordine por las disposiciones de las fuentes correspondiente), en los acuerdos del MERCOSUR está regulado a texto expreso.

Validez del Acuerdo Arbitral: En materia de validez de la cláusula arbitral no fue recogida explícitamente en la LNA ni la LNAU, simplemente se establece que dicha condición de validez se sujetara a "en virtud de la ley a que las partes lo han sometido "y subsidiariamente se regirá por la ley de la sede del arbitraje.

Una tercera causa contra la denegación del reconocimiento extraterritorial del laudo obedece a "que la parte contra la cual se invoca el laudo no ha sido debidamente notificada de la designación de un árbitro o de las actuaciones arbitrales o no ha podido, por cualquier otra razón, hacer valer sus derechos" art. 104 LNA (igual regulación vemos en la Convención de Nueva York, CIDIP-I sobre ACI y acuerdos MERCOSUR).

Una cuarta causal responde a la incompetencia del TA por haber fallado sobre determinados aspectos, al no estar estos subsumidos dentro del compromiso arbitral y por lo tanto el mismo no tener capacidad para resolver sobre dicha área, o que la propia composición del TA no se realizó de conformidad con lo dispuesto en el acuerdo arbitral o con las leyes de procedimiento.

En cuanto a la posibilidad de denegar la continuidad jurídica del laudo en base a la Arbitrabilidad, el OP y la excepción de OPI, hemos expuesto la visión en un capítulo precedente. Cabe mencionar, no obstante que dicho análisis será realizado por la autoridad jurisdiccional que reciba el mismo.

Es de recibo afirmar que la LMU aprobada por Uruguay y Argentina mantuvo un criterio uniforme con las demás fuentes supranacionales en la materia evitando así la colisión de soluciones, por causa de que los aspectos comprendidos en la Convención de Nueva York aplican casi a la totalidad de los países. Tal como nos señala la doctrina norteamericana, su efectividad se basa en tres pilares: 1) la obligatoriedad de reconocimiento por parte del estado; 2) la obligación de reconocimiento del tribunal arbitral por parte del poder judicial; y 3) el corolario establecido por el art. V (Gómez, 2006).

\section{ARMONÍA LEGISLATIVA}

Este apartado se referirá a la interacción que se da entre las distintas fuentes del DIPR sobre ACI. Para ello analizaremos someramente cómo interactúan las fuentes supranacionales, para luego apreciar algunos aspectos interesantes que trataron a texto expreso la LNA y la LNAU. Una primera distinción podría versar sobre la siguiente cuestión: Ante un texto jurídico de fuente supranacional y uno de fuente nacional, ¿existe algún criterio para distinguir la fuente aplicable? 
Si bien podríamos evocar la dicotomía entre monismo o dualismo, resolveré esta cuestión recurriendo al principio non sunt multiplican sentia sine necesitatis. Con este fin, acudo a la normativa vigente de Fuente Universal, Regional, Subregional y Nacional ${ }^{44}$ que establece la primacía de la fuente supranacional a la nacional. Una segunda cuestión implica distinguir entre tipos de Arbitraje, en otras palabras, que esta ley tiene por función ontológica regular al ACI y no al arbitraje entre sujetos del derecho internacional o de derecho público interno.

En materia de armonía legislativa, la dicotomía puede se origina a partir de la existencia de normativa de igual jerarquía y con un mismo objeto regulado. En este caso podemos apreciar una norma de carácter excepcional, dada por el art. 30 de la Convención de Viena sobre Derecho de los Tratados de 1969. En igual sentido, el art. VII de la Convención de Nueva York que establece que las disposiciones de dicha convención "no afectarán la validez de los acuerdos multilaterales o bilaterales..." suscritos en la materia, sino que siempre se aplicará buscando el interés superior de la preservación y continuidad jurídica del ACI. A partir de la lectura atenta del presente artículo surgen algunos aspectos a destacar. En primer lugar, no establece restricciones de carácter "temporal"45. Tampoco existe disposición alguna con respecto a normas anteriores (o posteriores) a su aprobación, ni se abordan cuestiones de jerarquía, siendo estos aspectos muy importantes a la hora de la interpretación normativa. En su nota explicativa al art. II del convenio de Nueva York, la UNCITRAL establece que:

"el párrafo 1 del Artículo VII (...), se aplica de forma que permita a toda parte interesada acogerse a los derechos que puedan corresponderle en virtud de las leyes o tratados del país donde se invoca el acuerdo de arbitraje, para obtener el reconocimiento de la validez de ese acuerdo de arbitraje. $46 "$

En cuanto al ámbito Interamericano tenemos que la CIDIP-II sobre Eficacia de Sentencias, la cual establece claramente un criterio de armonización al expresar que" las normas de la presente convención se aplicarán en lo relativo a laudos arbitrales en todo lo no previsto en la Convención Interamericana" sobre ACI. Los acuerdos del MERCOSUR, "no contienen cláusulas de compatibilidad." No obstante, los art 23 y 25.3 "adoptaron por otra estrategia, remitiéndose a otros textos convencionales" (Rubén Santos, 2006).

La UNCITRAL establece en el proyecto de ley modelo que" La presente Ley se aplicará al arbitraje comercial internacional, sin perjuicio de cualquier tratado multilateral o bilateral vigente en este Estado.". Confirmando la preeminencia de la normativa supranacional sobre la nacional. Presentándose conjuntamente como paraguas jurídico que rellene los aspectos no regulados por dichas fuentes. Destacando que la ley argentina prevé una forma

\footnotetext{
44 Art 27 de la Convención de Viena sobre Derecho de los Tratados; Art 1 Convención de Normas generales de DIPR Art Protocolo Adicional a los Tratados de Montevideo de 1889-1940 Art 525 Código General del Proceso y el Art 2594 del Título IV (sobre normas de DIPR) del Código Civil y Comercial de la Nación Argentina.

45 Como si lo establece el Protocolo del Valle de las leñas el cual expresa en su artículo 35 que no se restringirá las disposiciones de las convenciones que sobre la misma materia hubieran sido suscritas anteriormente entre los Estados parte mientras no se contradigan (no estableciendo disposiciones a posteriori)

46 Disponible en https://www.uncitral.org/pdf/spanish/texts/arbitration/NY-conv/New-York-Convention-S.pdf
} 
de interpretación no exhaustiva del art II.2 de la Convención de Nueva York según lo dispuesto en el art 106 de la LNA. ${ }^{47}$

\section{CONCLUSIONES}

En la presente investigación se ha dado cuenta sobre la influencia de la LMU de ACI, en la unificación del SI (en su proyección jurídica y económica), tomando como caso de estudio a Uruguay y Argentina.

Medularmente, es imperante destacar sin mayores dilataciones, que efectivamente La aprobación de la Leyes 19.636 y $\mathbf{2 7 . 2 4 4}$ en los ordenamientos jurídicos uruguayo-argentino en el 2018 coadyuvó a la unificación del Sistema Internacional. Dicha afirmación se realiza en base a los siguientes postulados. En primer lugar, expresamos que en 2018, Uruguay y Argentina culminaron un proceso iniciado en 1889, con el art. 5 del Tratado de derecho procesal internacional, al incorporar normativa que reconocía el ACI en su fuente nacional, superando las regulaciones dadas por los códigos procedimentales, evitando de esta forma los trabajos de ingeniería y milagros jurisprudenciales al no tener una normativa correcta). Esto determinó el inicio de un mejor relacionamiento a nivel internacional, así como la armonización de soluciones en materia de DIPR.

El llamado a la armonización de soluciones ya había sido respondido en el ámbito del MERCOSUR (al cumplir el art. 1 del Tratado de Asunción) aprobando dos protocolos sobre ACI. De igual modo, debemos comprender que la inserción comercial de ambos países no debe quedar acotada sólo al ámbito sur-interamericano; es razonable e inteligente ampliarse a una comunidad con un número más elevado de países. Es de la mano del ACI que se puede salir a buscar mercados y promover los negocios, brindando la certeza jurídica de que en casos de controversia existan un sistema jurídico moderno, rápido y eficaz. Ahora bien, esta transformación legislativa llevó a una reestructuración de las soluciones en torno al ACI para ambos países.

El primer elemento por visualizar es el Anwendungsbereich (y en especial los temas de internacionalización), el cual nos permite tener claro qué tipos de arbitraje le serán subsumibles, por lo que consagra un sistema dualista (al regular el arbitraje interno a través de los códigos procedimentales y el ACI por las leyes nacionales en base a la LMU).

En esta área, observamos una de las primeras innovaciones de las Leyes Nacionales de arbitraje: la determinación un criterio de internacionalidad perfectamente armonizable con el sistema de DIPR de ambos países, debido a que se adoptaron criterios ya consagrados en la Convención de Viena sobre Compraventa Internacional de Mercaderías de $1980^{48}$ (sumado el criterio del lugar de cumplimiento de una obligación sustancial de las obligaciones o el lugar objeto del litigio dependiendo con cual tenga la conexión más estrecha).

47 En el derecho comparado europeo nos encontramos que el Art 46 de la Ley de ACI en España establece que "el exequátur de laudos extranjeros se regirá por el Convenio de Nueva York de 1958, sin perjuicio de lo dispuesto en otros convenios internacionales más favorables a su concesión" (Esplugues, 2010).

48 Este criterio a su vez no solo es de recibo para los países que adhirieron la ley modelo. Sino que se suma a la inmensa cantidad de países que suscribieron a la C. Viena del 80 antes mencionada. Mientras que es un elemento internacionalizador de amplia aceptación en todas las comunidades jurídicas. 
En cuanto a la LNA, se lograron dos aspectos fundamentales. El primero de ellos fue lograr que esta ley fuera determinada como prórroga de jurisdicción y no procesalista (si se subsumía dentro de esta última consideración, el gobierno federal no tendría competencias para sancionarla, y hubiese tenido que ser aprobada provincia por provincia). Una segunda cuestión (consagrada en ambos países, pero con especial interés para Argentina) es el exclusivismo. Puesto que la LNA estableció que el ACI sería regulado exclusivamente por dicha ley, (como ya fue expuesto). En materia de interpretación se destaca el desarrollo progresivo del DIPR en tanto que se tienen en cuenta elementos específicos para interpretar las normas de ACI. Sin perjuicio que siempre tendremos los Art 15 a 17 del Título Preliminar de las leyes del CC en Uruguay y el Art 2 del CCCN. Uno de los aspectos sobre los cuales la normativa recientemente aprobada no establece disposiciones (literalmente), refiere a los aspectos de la Arbitrabilidad, los cuales aún seguirán subsumidos en el ámbito del derecho interno de conformidad con las normas de orden público.

Considerando los aspectos de la Arbitrabilidad, debemos expresar que la ley Modelo UNCITRAL no ha querido expresare con respecto a dicha materia. Ya sea porque lo considera un aspecto vinculado a los elementos sobre los cuales los Estados asientan su individualidad jurídica (puesto que involucra temas de OP y OPI). Otra razón puede venir dada por la falta de consenso jurídico en cuanto a la materia arbitrable, y en ese sentido se entiende que no quisiera agregar disposición al respecto, pues sería poner un obstáculo a los países para la interiorización de dicha legislación modelo.

Considerando el Derecho aplicable a los distintos aspectos del arbitraje comercial internacional se aprecia primeramente la materialización jurídica de estos, a consecuencia de que no existían en la legislación anterior. Destacando además la consagración de la autonomía de la voluntad ${ }^{49}$ en materia de elección de las reglas procesales que regirán el arbitraje y el derecho que se aplicara al fondo del asunto. En cuanto al acuerdo arbitral se siguen algunos principios emanados de la normativa ya vigente en ambos países. Aunque se eliminan algunos elementos tales como la necesidad de escritura pública para la concreción del acuerdo (como preveían los códigos de procedimiento civil de ambos países) y no se recogen otros tales como la posibilidad que se realice por escrito.

En materia de impugnación y reconocimiento y ejecución del laudo arbitral, la aprobación de las LM nos permite realizar la distinción clara entre ambos elementos. Comprendiendo que la impugnación es un mecanismo procesal realizado a instancias del tribunal arbitral, el cual no es sujeto a recursos y que establece cosa juzgada. El reconocimiento y ejecución no son más que un mecanismo procesal internacional de eficacia extraterritorial, que no analiza las cuestiones de fondo, (no es una doble impugnación), sino que examina temas formales, documentales y procesales para darle continuidad jurídica. Siendo el único elemento de fondo la existencia de un OPI en virtud de la materia objeto del arbitraje.

Analizando la diversidad de normas que existen sobre la materia, apreciamos un alto nivel de "inflación legislativa". Por lo cual se nos plantea el tema de la armonización

49 Este criterio a su vez no solo es de recibo para los países que adhirieron la ley modelo. Sino que se suma a la inmensa cantidad de países que suscribieron a la C. Viena del 80 antes mencionada. Mientras que es un elemento internacionalizador de amplia aceptación en todas las comunidades jurídicas. 
legislativa. En el cual se destaca que las leyes nacionales vienen a complementar todos los tratados existentes. Es decir, que aquellos elementos que no se encuentren regulados en los dos grandes textos macro (Convención de Nueva York y la Interamericana) serán complementados con las leyes nacionales. Esto también podría pasar con los protocolos del MERCOSUR, los cuales ya regularon la mayoría de los temas que comprenden las leyes modelo.

En cuanto a la unificación de soluciones del DIPR es de recibo realizar alguna consideración. La primero de ellas es que en el Sistema de DIPR observamos una flexibilización y una promoción del softlaw. Puesto que la incorporación de normativa inspirada en "leyes modelo" de aplicación universal y basada en la experiencia de los actores del comercio internacional nos permite tener regulaciones que acompañen (en términos de Heráclito) el devenir de las cosas y del logos (conocimiento). Puesto que, si subsumíamos estas regulaciones en tratados, estaríamos generando (en términos de Aréchaga y Charles Rousseau) un derecho estricto de difícil modificación (es decir una trasformación del comportamiento de los actores y la operacionalización de las variables intervinientes según el método axiomático). Vale aclarar además que, si bien no son objeto del presente trabajo, los principios UNIDROIT y los INCOTERM también siguen esta lenta pero inexorable-le trasformación del DIPR.

En un segundo lugar observamos que dichas acciones representan una trasformación de la propia concepción del DIP, el cual nació para solucionar las colisiones de soberanía creando complejos sistemas de conflicto, a ser el generador de un sistema de autorregulación de los conflictos entre los particulares a través de los ADR. Garantizados en su continuidad jurídica extraterritorial por las distintas autoridades estaduales.

Por lo tanto, afirmamos que el mundo asiste a una transformación de carácter civilizacional como no ocurría desde el paso de la edad media a la época moderna, esta última estuvo signada por la transformación de los feudos en Estados Nacionales, y los viejos señores feudales sustituidos por los Monarcas "absolutos". Estos monopolizaron el uso legítimo de la fuerza, la creación de moneda y la impartición de justicia (aunque en mayor o menor medida el arbitraje siempre sobrevivió). En el marco de la caída de las monarquías con las revoluciones burguesas y el advenimiento de las democracias liberales asistimos a los primeros cambios cualitativos dado por el incentivo de las libertades individuales, las cuales generaron un aumento de la producción y la distribución de la renta (disminuyendo exponencialmente la pobreza y las desigualdades).

En este marco se aprecian los primeros intentos de fomentar la cultura arbitral, tanto en el ámbito del DIP como en el DIPR. Estos se vieron bloqueados por la era de los imperialismos y el concierto europeo que culminaron en la I y II Guerra Mundial y posteriormente la Guerra Fría. Esta última dividió al mundo en dos (democracia versus economía planificada) restringiendo el pacífico desarrollo del comercio internacional. Después de la caída del muro de Berlín, la imposición del liberalismo como identidad cultural ideal para el bloque occidental y la promoción de una economía libre y competitiva, observamos una desmonopolización de algunas funciones que el Estado se había abrogado como exclusivas (creación de la moneda, seguridad e impartición de justicia), 
fomentando (a través de los instrumentos jurídicos estudiados) una plataforma de seguridad jurídica para la pacifica solución privada de controversias entre los distintos actores para-estatales del Comercio Internacional. Recordando la mítica frase...donde entra el comercio no entran balas, podemos asegurar que la promoción de los medios alternativos para los conflictos comerciales internacionales posibilitase un mayor entendimiento entre los distintos actores del SI generando consigo unas RRII más pacíficas.

En definitiva, en la construcción del Orden Mundial post caída de la URSS, (con el ingreso de China a la $\mathrm{OMC}$, los nuevos debates en torno al medio ambiente, las competencias del FMI, la desarticulación del Multilateralismo, la crisis de la OMC y la retroversión de los Estados a las lógicas nacionales del siglo XX) apreciamos, a pesar de los coletazos mencionados, un desmantelamiento de la visión clásica de las RRII y el Estado Nacional, debido a que los individuos están resolviendo sus diferendos ante autoridades no gubernamentales, provocando un divorcio de determinadas parcelas de la realidad internacional.

\section{BIBLIOGRAFÍA}

ALFONSÍN Quintín. Teoría del Derecho Privado Internacional. Biblioteca de Publicaciones Oficiales de la Facultad de Derecho y Ciencias Sociales de la Universidad de la República, Uruguay. 1961.

BERMÚDEZ Abreu Yoselyn. (10/03/08). Algunas consideraciones sobre la Armonización en el Derecho Internacional Privado. Revista de Ciencias Jurídicas, No 116 mayo-agosto 2008, 139-170. 2008

BOOGGIANO Antonio. Derecho Internacional Privado. Tomo II. Abeledo Perrot, Argentina. 1991

BORN Gary. International Arbitrations: Law and Practice. England: Wolters Kluwer. 2011

CADENA Xavier Andrade. Las Ventajas del Arbitraje Internacional: Una Perspectiva Ecuatoriana. Revista de Derecho Comparado, Rubinzal - Culzoni. 131-166. 2011

CAIVANO Roque J. El Rol del poder Judicial en el Arbitraje Comercial Internacional. En Arbitraje Comercial Internacional OEA (97-127). Washington: OEA. 2006

CALVO Caravaca, Alfonso y Luis Fernández de la Gándara. (1989). El arbitraje comercial internacional. Madrid: Tecnos. 1989

CARBONNEAU E Thomas. Arbitrations Nutshell Series. EEUU: West. 2007

CONEJERO Roos Cristián. La influencia de la Ley Modelo de la CNUDMI sobre Arbitraje Comercial en América Latina. Un análisis Comparativo. Revista Chilena de derecho Número 32 enero Abril. 2005

COUTURE, Eduardo J. (año). Estudios sobre el derecho procesal civil. Vol. 3. El juez, las partes y el proceso. La Ley. 1959 
DIAZ Soledad Rothschild Julie Ruanova Mariela. El Acuerdo de Arbitraje Comercial Internacional en el MERCOSUR. Revista Universidad de Montevideo, 11. 2007

DIEZ de Velasco en Velazco Manuel. Las Organizaciones Internacionales, 14 ed, Madrid. 2004

DRAHOZAL R Christopher. Regulatory competition and the location of international arbitration proceedings. International Review of Law and Economics, Volume 24. Issue 3, 371-384. 2004

EDUARDO Jiménez de Aréchaga. Derecho Internacional Público. Tomo IV. Fundación de Cultura Universitaria. 2015

EYZAGUIRRE Siqueiros J, LArbitration in Latin American Countries ICCA Series. 1989

FABVRE-Bulle Xavier. Are Arbitration Proceedings Still Exclusively for the parties. EnTowars a uniform International Arbitration Law (203-245). ginebra: Staempfi Publishes. 2004

FRESNEDO Cecilia. El Acuerdo Arbitral como piedra angular del arbitraje. El rol de la judicatura en el control de su validez. págs. 169-203 OEA. 2006.

Curso de Derecho Internacional Privado Parte General FCU. 2013.

Capítulo X El Arbitraje Comercial Internacional: Presencia y evolución en el ámbito jurídico uruguayo pág. 217-250 de Derecho Procesal Transnacional Homenaje al profesor Doctor Gualberto Lucas Sosa Editorial Abaco de Rodolfo Depalma. 2012

GOMEZ, Manuel. Arbitraje Comercial Internacional, La difícil relación entre anulación y el reconocimiento y ejecución del laudo arbitral internacional, página 295-307 EEUU, OEA. 2006

GUERRA Walter. Código General del Proceso con apéndice normativo. Ediciones del Foro Montevideo, Uruguay. 2015.

GIUFFRA Carolina. Teoría y Práctica del Proceso Arbitral en el Código General del Proceso. Fundación de Cultura Universitaria. Montevideo, Uruguay. 2007

ILJA Alexandrow. InternationaleSchiedsgerichtsbarkeit in Deutschland und in den GUS-Staaten. Germany: Ruhr-Universität Bochum. 2002

RIVERA Cesar Julio. Ley de Arbitraje Comercial Internacional Revista de Legislación Uruguaya Año IX Número 5 La Ley págs. 185-205. 2018.

NNUU Anuario de la Comisión de Naciones Unidas para la Unificación del Derecho Mercantil Internacional Volumen I. 1970. 
LOUWAS a Mistelis. Arbitrability international and comparative perespectives Is Arbitrabiliti a antional or international law issue. En Arbitrability international and comparative perspectives (1-15). United Kingdon : Wolter Kluwer. 2008.

OLIVERA Garcia Ricardo. La ley de Arbitraje Comercial Internacional Primeras reflexiones Revista de Derecho Comercial Año III Número 12 página 33-65. 2018.

OLMEDO Hernán. Historia Mínima de las Teorías de las Relaciones Internacionales Documentos de Trabajo, Facultad de Ciencias Sociales, Montevideo. Uruguay. 2018.

OPPETIT, Bruno. Teoría del Arbitraje. Bogotá, Colombia: Legis Editores SA ReveloAvila Andrea. 2006

Arbitraje Internacional de Inversiones como Mecanismo de Solución de conflictos, como Estado Soberano, y los Inversionistas Extranjeros. México: Universidad de las Américas. 2011

RUIZ Gonzalez Ana Maria. El Arbitraje Internacional y la Teoría de Savigny en el Derecho Internacional Privado. En Tesis para Optar al rado de Licenciatura en Derecho (1-95). San José, Costa Rica: Universidad de Costa Rica.

SANTOS Belandro Rubén. Arbitraje Comercial Internacional Tercera Edición Oxford.

Seis lecciones sobre Arbitraje privado (interno e internacional). Uruguay: Asociación de Escribanos del Uruguay.

El derecho aplicable en el arbitraje comercial internacional de acuerdo a la ley $\mathrm{N}$ 19636. Uruguay:

La Pluralidad de los Tratados y de Legislaciones en Relación con el Arbitraje Comercial Internacional. En Arbitraje Comercial Internacional OEA (49-60). Estados Unidos: OEA.

SCHOUTEN Peer. Teoría social de la política internacional Alexander Wendt y el constructivismo social en las Relaciones Internacionales. Universidad Complutense de Madrid, Academia.Edu, 2007.

SCHWARTZ Alam Scott Robert. The political economy of private legislatures. Universityof Pennsylvania Law Review, VOL. 143, 595-654. 1995.

STEPHAN Paul B. The Futility of Unification and Harmonization in International Commercial Law. University of Virginia School Law Legal Studies Working Papers Series, Working Paper, No. 99-10. 1999.

REINMAR Wolff, Marburg. Liber Amicorum Böckstiegel, Grundzüge des Schiedsverfahrensrechts. Germany: Hesse. 2008.

TELLECHEA Eduardo. (2002). La Dimensión judicial del caso privado internacional en el ámbito regional FCU Uruguay. 2002. 
TALICE Jorge. Interpretación e Integración del Derecho Internacional privado Montevideo Uruguay. 1974.

Arbitraje Comercial Internacional, Internacionalidad y derecho de fondo aplicable en la ley 19636 del 26 de julio de 2018 sobre arbitraje comercial internacional. La Ley Montevideo Uruguay. 2019

UNCITRAL. La guía de la CNUDMI Datos básicos y funciones de la Comisión de las Naciones Unidas para el Derecho Mercantil Internacional. Viena: Naciones Unidas. 2007.

UNITED Nation conference on trade and development T. (2017). World investment report and the digital economy 2017. Geneva: UNITED NATIONS PUBLICATION. 2017

VIVIANA Tepfer. (.). Una puesta el día en la legislación sobre Arbitraje en Argentina. 20 de enero del 2019, de Universidad de Buenos Aires Sitio web: http:/ /www.derecho. uba.ar/publicaciones/lye/revistas/84/08-winitzky-tepfer.pdf

ESPLUGUES Mota Carlos, Iglesias José Luis, Palao Guillermo. (2016). Derecho Internacional Privado. España: Tirant lo Blanch. 